\title{
ANALYSIS AND VISUALIZATION OF NATURAL THREATS AGAINST THE SECURITY OF ELECTRICITY TRANSMISSION SYSTEM
}

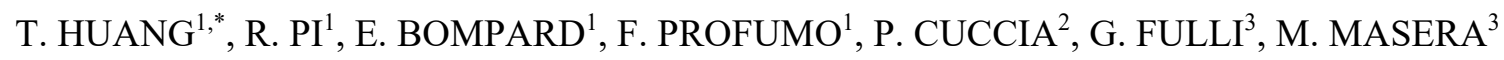 \\ ${ }^{1}$ Dipartmento Energia, Politecnico di Torino, Torino, 10129, Italy \\ ${ }^{2}$ Terna Rete Italia SpA, Via S. Botticelli, 139, Torino, 10154, Italy \\ ${ }^{3}$ Joint Research Center of the European Commission, Via Enrico Fermi, 2749, Ispra VA, 21027, Italy \\ E-mail: tao.huang@polito.it
}

\begin{abstract}
Electricity is one of the crucial energies of modern society, but it is greatly threatened by various kinds of menaces, especially natural hazards. Although they rarely happen, their occurrence may hugely affect the operation of power system. In this paper, we firstly, according the impact on power systems, classify natural threats into two categories (natural disasters and extreme weather conditions) and several subcategories (geological, hydrological, meteorological and climatological). Then the changes in natural threats to power systems and their trends during recent decades are discussed, along with a review of events that pose natural threats to the power system. Finally, the georeferenced model based on the Italy transmission system for natural threats analysis is presented.
\end{abstract}

Keywords: Natural threats, Georeferenced model, Steady state contingency analysis, Italian power system

\section{INTRODUCTION}

Electricity system, widely exposed to the natural environment, is vulnerable to different threats such as natural threats, accidental threats, and malicious threats [1]. Many natural disasters recorded in the history already demonstrated their considerably negative impacts on power systems [2]. For example, Hurricane Katrina, according to the survey of National Climatic Data Center, caused over 1.7 million people without electricity for several weeks and the total economic losses were estimated to exceed $100 \mathrm{G} \$[3]$. Wenchuan earthquake in China, disturbed the operation of 21 power plants with total installed capacity of $3.2 \mathrm{GW}$ and led to about $140 \mathrm{G} \$$ economic losses $[4,5]$.

Global economic losses caused by natural disasters are on the rise [4]. Basically, the increasing need of electricity due to the growth of population and the relative use and the development of power systems have resulted in increasing damages due to natural disasters. It is, however, difficult to quantify the impact of the climate change effect up to now because the related events are exceptional. Therefore, multiple countermeasures, such as new investment, protection plans, emergency action plans are developed with acceptable costs to limit the impacts of unexpected detrimental events. Although it is obvious that power systems would suffer great damages from natural disasters, it is hard to improve the power transmission system security against natural disasters in the short run, as the investment in power system reinforcement is a long-term project. For example, building a high voltage transmission line on average takes 10 to 15 years (the timelines includes planning, scoping, mapping, environmental review, public comment, project approval, permitting, land acquisition and construction) [6]. Therefore, it is necessary to understand the ramification of natural threats on power systems and develop proper approaches and tools to efficiently identify and further reduce the negative consequences.

Studies about natural threats on power systems already drew much attention. Reference [7] briefly introduced worldwide natural disasters resulting in serious damage to the energy infrastructure, loss of lives and properties. Reference [8] introduced an earthquake happened on August 17, 1999 in Turkey, which destructively affected the Turkish power system. The total loss of load roughly reached to $7.0 \mathrm{GW}$, which was about $30 \%$ of a total load of Turkey. Reference [9] concluded how a catastrophic winter storm affected power system in China. From January to February in 2008, south part of China has suffered from the most destructive winter storm since 1920 and experienced large-scaled blackouts in Guangxi, Guizhou, Yunnan and Guangdong provinces. The total losing power amounted to 6,209 GW. Those papers only used statistics to present the loss related to power systems. In this paper, we established a georeferenced transmission network model combining a realistic static power system model and geographic information system to provide an effective tool to enhance the visualization of natural threats against the operation of power systems. More specifically, this model can offer illustrative diagrams to intuitive recognize the affected areas and system operational security situation after some adverse natural events happen. In some cases, it is necessary to conduct dynamic studies to understand the associated stability problems. However, the dynamic simulation is only meaningful after we can achieve a static operation point.

The remainder of this paper is composed as follows. In Section 2, we provide a classification of natural threats and discuss their possible impact. In Section 3 and 4, we discuss the evolution of natural threats and present a list of past natural-related failures in the power system. In Section 5, we introduce the georeferenced model of power transmission systems based on the Italian case. In addition, we provide the security analysis against two 
natural events as examples, which are cooperated with the Italian transmission system operator. Some conclusive remarks are drawn in Section 6.

\section{NATURAL THREATS AGAINST POWER SYSTEMS: CLASSIFICATION AND IMPACT}

Various definitions of natural threats have been proposed before. Reference [10] suggested that, from the geographic perspective, the natural threats are the potential negative damages on the earth caused by the natural disasters such as earthquake, tsunami, flood, etc., while a natural disaster is the extreme hazardous event that occurs to influence on communities causing disruption, damage, and casualties, and the affected communities cannot function normally without additional assistance. Reference [11] defined them as all atmospheric, hydrologic, geologic and wildfire phenomena that, has the potential to affect the human health, activities or even the constructions.

In this paper, considering the involvement of power system, we define natural threats as a potential event or a set of events happen around the world with different scales (local, national, continental) and different short time frames (instantaneously, minutes, days), and it is not directly involved by human's activities but it would affect the operation of power systems with a large scale disruption of electricity supply.

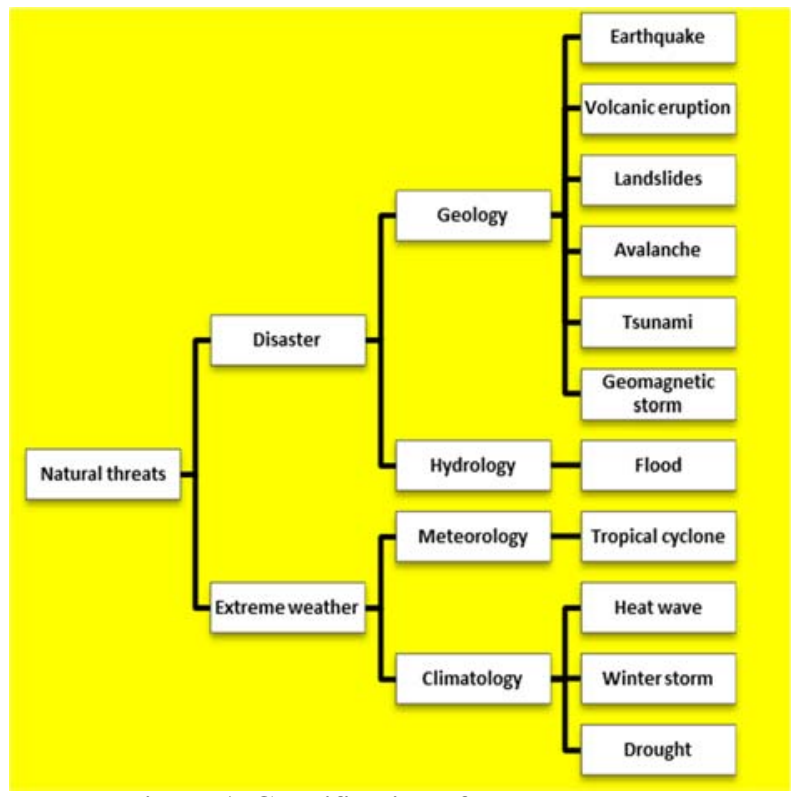

Figure 1. Classification of natural threats

Based on the definition of natural threats, we proposed a classification for studying their impact on electricity infrastructures. Natural threats can be classified into two main categories (disaster and extreme weather condition) and several sub-categories (geological, hydrological, meteorological, and climatological). Figure 1 shows the classification of the most typical natural threats against the secure operation of power systems.
It should be noted that the difference between "meteorology" and "climatology" mainly lies in the time perspective. Meteorology is intended to indicate the weather conditions over the short-term while climatology employs a long-term perspective [2].

With references to Figure 1, the sub-category can be further defined as follows. An earthquake is the ground shaking caused by movement under the earth's surface [12]. A volcanic eruption means a volcano sends out ash clouds, lava and even volcanic bombs [11]. A landslide refers to masses of rock, earth or debris moving down a slope [11]. An avalanche is a mass of snow, often mixed with ice and debris which travels down mountainsides, destroying all in its path [11]. A tsunami is a series of enormous waves created by an underwater disturbance [11]. Geomagnetic storms are created when the ionized particles carried by the solar wind because of coronal mass ejections or coronal holes at the Sun are captured by Earth's magnetic field [13]. A flood is a land covered by water that is not usually covered by water [14]. A tropical cyclone is a rotating, organized system of clouds and thunderstorms that originate over tropical or subtropical waters and has a closed low-level circulation (Hurricane, tornado, and typhoon are the same phenomena in different places) [15]. A heat wave is an extended period of extreme heat and is often accompanied by high humidity [14]. A winter storm is an event in which the main types of precipitation are snow, sleet or freezing rain [14]. A drought is a lengthy period of time, stretching months or even years in which time land has a decrease in water supply [14].

Bulk power systems are easily threatened by natural disasters due to the large exposure to the environment. However, the components of a power system such as generator, transformer, substation, overhead line, cable, control center, etc., can be affected differently by natural threats [16]. In general, earthquakes could damage all power system equipment, and are most likely to cause power interruptions lasting more than a few days. Tropical cyclones primarily affect transmission and local distribution systems, while floods could damage the generating equipment as well. Although heat waves and droughts normally cannot straightforwardly destroy elements of the power system, unless the temperature reaches extremely high, they can significantly increase the cooling/air conditioning consumption while decrease the generation capacity of hydrological power plants. However, under extreme situations, flood can damage or put out of service the underground substations or control centers, whereas heat waves may trip transformers or overhead lines due to the temperature protection or short circuits caused by the elongation of the wires. Geomagnetic storms usually damage bulk power system associated with transformers. In terms of the winter storm, the ice may result in the damage of transmission towers or short circuits in substations. Table 1 shows the potential impact on power system from almost all common natural 
threats, which is based on the assumption that all the events are serious.

Table 1. Natural threats in power system: threatened components and impact

\begin{tabular}{|c|c|c|c|c|c|c|c|c|c|}
\hline & \multicolumn{6}{|c|}{ Threats to power ystem } & \multicolumn{3}{|c|}{ Posible impact } \\
\hline & Geaerator & Transformer & Substation & $\begin{array}{l}\text { Overtead } \\
\text { liate }\end{array}$ & Cable & $\begin{array}{l}\text { Control } \\
\text { center }\end{array}$ & $\begin{array}{c}\text { Equipment } \\
\text { damage }\end{array}$ & $\begin{array}{c}\text { Stort } \\
\text { circults }\end{array}$ & Overtoad \\
\hline Eartaquake & H & B & H & H & н & н & $\checkmark$ & v & \\
\hline $\begin{array}{l}\text { Volkanic } \\
\text { cruption }\end{array}$ & н & н & н & н & $\mathrm{s}$ & Н & $\checkmark$ & $\checkmark$ & \\
\hline Landstide & H & H & H & H & $\mathrm{s}$ & H & $\checkmark$ & $\sqrt{ }$ & \\
\hline Avalanche & н & н & H & H & $\mathrm{s}$ & H & $\checkmark$ & $\sqrt{ }$ & \\
\hline Tsunami & H & H & H & H & $\mathbf{s}$ & H & $\checkmark$ & $\sqrt{2}$ & \\
\hline $\begin{array}{l}\text { Geomagnetic } \\
\text { storms }\end{array}$ & $\mathrm{s}$ & н & $\mathrm{s}$ & $\mathrm{N}$ & $\mathrm{s}$ & н & $\checkmark$ & & $\checkmark$ \\
\hline Flood & H & H & $\mathbf{s}$ & M & $\mathrm{s}$ & $\mathrm{s}$ & $\checkmark$ & $\checkmark$ & \\
\hline $\begin{array}{l}\text { Tropical } \\
\text { cyclone }\end{array}$ & н & н & н & н & $\mathrm{x}$ & H & $\checkmark$ & $\checkmark$ & \\
\hline Heat wave & H & $\mathbf{x}$ & $\mathbf{N}$ & $\mathbf{x}$ & $\mathrm{x}$ & $\mathbf{N}$ & & & $\checkmark$ \\
\hline $\begin{array}{l}\text { Winter } \\
\text { storm }\end{array}$ & M & st & $\mathrm{s}$ & н & $\mathrm{s}$ & $\mathrm{N}$ & $\checkmark$ & $\sqrt{ }$ & $\checkmark$ \\
\hline Drought & M & $\mathrm{x}$ & $\mathrm{x}$ & $\mathrm{x}$ & $\mathrm{x}$ & $\mathrm{N}$ & & & $\checkmark$ \\
\hline
\end{tabular}

\section{DISTRIBUTION OF NATURAL HAZARDS}

The occurrence of adverse natural events is random and irregular, but it was recorded with an upward trend in the last decades [16]. According to reference [17], the total number of adverse natural events showed an ascendant overall trend during recent 60 years (1950-2010). There are 450 events in the year 2010, which is 18 times than the number of the year 1950 .

Besides the increasing frequency, natural hazards manifest in various forms and in different locations. In order to visualize the main natural hazards of each country/region, a map (Figure 2) with main natural threats of each country in the world was created based on the information collected from Centre for Research on the Epidemiology of Disasters (CRED) [18]. Furthermore, we provided another map with a special focus on Europe (Figure 3).

In terms of the criteria for coloring each country, it is according to the number of occurrence of adverse natural events (earthquake, volcano, flood, drought, avalanche/landslide and tropical cyclone) happened from 1974 to 2003.To justify the frequent natural disaster/disasters for each country, we provided Table 2 to divide three levels of frequency according to the occurrence of natural disasters. If the frequency of a natural disaster reaches "Moderate Frequency" or even "High Frequency" in Table 2 [16], we defined the natural disaster as the main natural threat in this country.

Taking China and Italy for instances, based on Table 3 which presents the occurrence of natural disasters in those two countries, we can conclude that earthquakes, floods, droughts, avalanches/landslides and tropical cyclones are the main natural threats in China, while earthquakes, floods, avalanches/landslides and volcanoes are the typical natural threats in Italy.

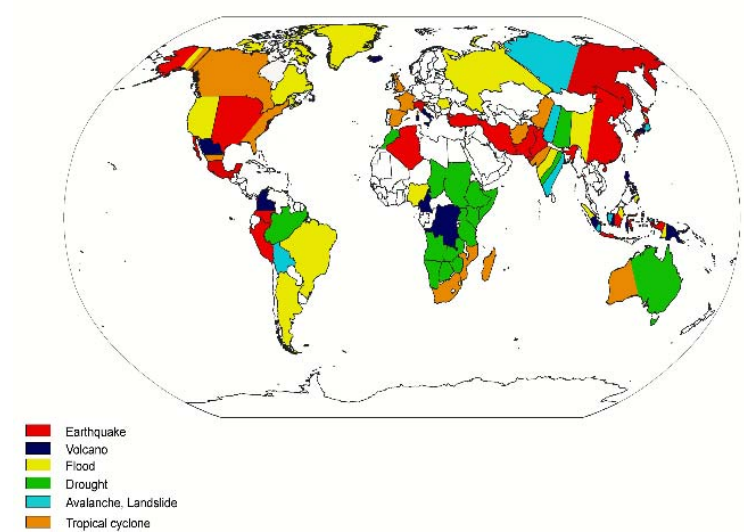

Figure 2. Main natural threats in the world

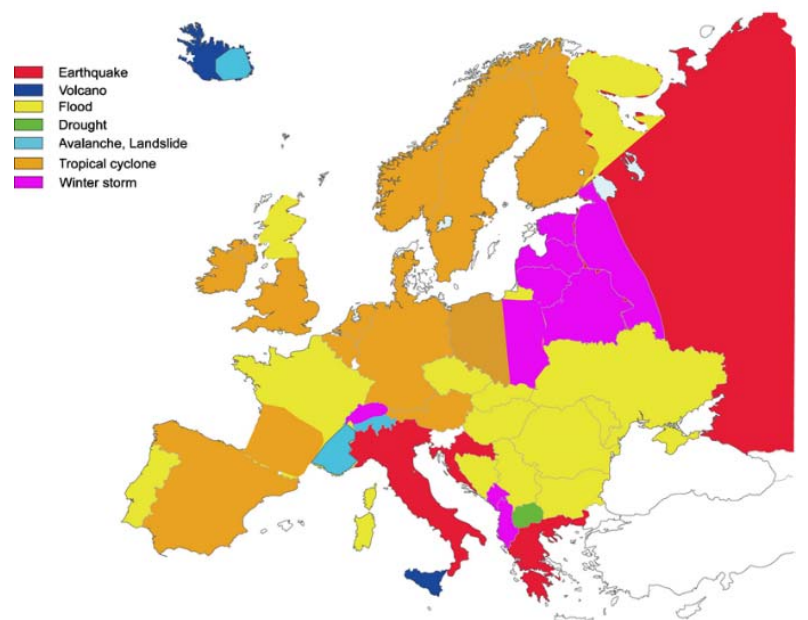

Figure 3. Main natural threats in Europe

Table 1. Frequency levels for the different natural disasters

\begin{tabular}{|l|l|l|l|l|l|l|}
\cline { 2 - 7 } \multicolumn{1}{c|}{} & Earthquake & Flood & Drought & $\begin{array}{l}\text { Avalanche/ } \\
\text { Landslide }\end{array}$ & $\begin{array}{l}\text { Tropical } \\
\text { cyclone }\end{array}$ & Volcano \\
\hline $\begin{array}{l}\text { High } \\
\text { Frequency }\end{array}$ & $>10$ & $>60$ & $>10$ & {$[1135]$} & $>30$ & $>2$ \\
\hline $\begin{array}{l}\text { Moderate } \\
\text { Frequency }\end{array}$ & {$[610]$} & {$[1660]$} & {$[610]$} & {$[410]$} & {$[1130]$} & {$[12]$} \\
\hline $\begin{array}{l}\text { Low } \\
\text { Frequency }\end{array}$ & {$[05]$} & {$[015]$} & {$[05]$} & {$[03]$} & {$[010]$} & 0 \\
\hline
\end{tabular}

Table 2. The occurrence of natural disasters in China and Italy

\begin{tabular}{|l|l|l|l|l|l|l|}
\cline { 2 - 7 } \multicolumn{1}{c|}{} & Earthquake & Flood & Drought & $\begin{array}{l}\text { Avalanche/ } \\
\text { Landslide }\end{array}$ & $\begin{array}{l}\text { Tropical } \\
\text { cyclone }\end{array}$ & Volcano \\
\hline China & $>10$ & $>60$ & $>10$ & {$[1135]$} & $>30$ & 0 \\
\hline Italy & $>10$ & {$[1660]$} & {$[05]$} & {$[410]$} & {$[010]$} & $>2$ \\
\hline
\end{tabular}

\section{IMPORTANT HISTORIC POWER SYSTEMS FAILURES DUE TO NATURAL DISASTERS}

Table 4 shows some historical instances of natural hazards and how they brought the huge loss to power systems and the society. 
Table 4. Major adverse natural events against power

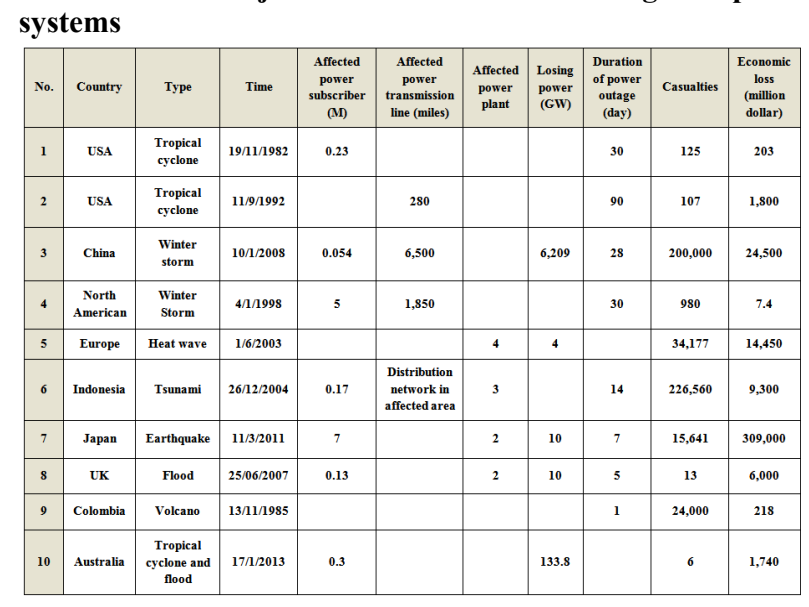

The tropical cyclones happened in 1982 and 1992 are two of the most severe natural disasters which posed huge threats to America's power grid. The total economic loss reached to about $2 \mathrm{GS}$, and the failure of critical equipment of power system caused a blackout for a few days [19], [20]. The winter storm happened on 1st April 1998 in North American caused 7.4 G\$ of economic loss, 980 casualties, 5 million people without electricity up to one month [21]. In addition, more than 3.5 thousand poles, 5 thousand transformers, and 1.3 thousand steel pylons were in need of repair [22]. The Indonesia Ocean tsunami of 16th December 2004 affected 1.7 million people, injured and killed 226,560 residents. Moreover, it produced $9.3 \mathrm{G} \$$ of economic losses, caused the power outage for 0.17 million power subscribers for 14 days, and resulted in abnormal operation at three power plants [23], [24]. Japan suffered from a large earthquake of magnitude 9.0 on 11th March 2011, and it brought about 15,641 casualties, $9.3 \mathrm{G} \$$ of economic loss, and no electricity for 7 million customers at the peak time. Additionally, threehour blocks of rolling blackouts were enacted sporadically throughout 10 prefectures during the summer of 2011 [25], [26]. A severe heat wave happened in Europe in June 2003 and continued through July until mid-August, which raised summer temperatures by $20 \%$ to $30 \%$ higher than the seasonal average temperature [27]. It also affected a large area which was extended from northern Spain to the Czech Republic [27]. With a death toll more than 30 thousand, the heat wave of 2003 become one of the most serious natural disasters in Europe for the last 100 years, and it ended up with a great financial loss at 14.5 G\$ [28]. Moreover, four nuclear power plants were forced to shut down because of the dramatic rise temperature of rivers used to cool the reactors, which engendered to loss $4 \mathrm{GW}$ power generation during the summer of 2003 [28]. Although there was no direct damage to the infrastructures of power systems, electricity demands dramatically soared due to the cooling loads.

A more complicated situation is that sometimes blackouts are attributed to combinations of multiple natural disasters. They are more complex than a single one as they often involve cascading events. Explanatorily, the primary failure triggers a sequence of secondary failures and failures of propagation will finally lead to a blackout in a large area. The event happened on 17th January 2011 in Australia was a typical instance. A tropical cyclone was first identified in the Gulf of Carpentaria on January 17th, but it became destructive wind and produced over 1,000 $\mathrm{mm}$ of rainfall in some areas during 48 hours. The major flooding within following weeks caused $133.8 \mathrm{GW}$ power outages, $1.7 \mathrm{G} \$$ economic loss and great impact on 0.3 million power customers [29].

\section{GEOREFERENCED MODEL FOR NATURAL THREATS ANALYSIS: AN APPLICATION TO THE ITALIAN POWER SYSTEM}

Georeferenced models in power systems are used for planning, reinforcing, monitoring, and managing the transmission networks. The sophisticated spatial analysis is greatly useful for formulating scenarios, determining optimum generation potential, studying environmental impact, and managing facility assets. Owing to the geographically-oriented view which combines the electric generation with transmission structures, devices, and network, a georeferenced model not only can be applied to the stability, protection and coordination, contingency analysis, and economic modeling, but also helps utilities to discover new issues about the investments and risks of building a transmission network, and allows the simultaneous assessment of technical, financial, and environmental factors [30].

The georeferenced model improves visualization of power systems by associating spatial data with transmission assets to display geographically referenced real-time power system data such as the voltage and line flow monitoring. Geographical information is stored in geographical map layers making it easy to integrate relevant information such as weather, vegetation growth, and road networks with related transmission network. Data of real-time weather integrated into a geographical map of power system increases the operator's situational awareness. For example, with the help of such model, the identification of a natural threat front moving towards a given area enables operators to rapidly determine transmission facilities with increased risks of outage [31].

Before introducing the Italian power system georeferenced model, the first thing is to be familiar with the typical disasters in Italy, and its electricity system.

Italy is a disaster-prone country with a high frequency of volcanic eruptions, earthquakes, floods and landslides. There are three active volcanoes named Mount Etna, Stromboli, and Mount Vesuvius, and six dormant volcanoes situated in southern part of Italy [32]. It is noted that Mount Etna and Stromboli are in an almost constant state of activity. The volcanic eruption which happened from 12th July 2001 and lasted for 24 days in Etna causing significant damage, mostly to the cable-car and ski-lifts located between 1.9 thousand and 2.6 thousand meters on the southern flank of the volcano [32]. In terms of the 
earthquakes, from 1900 to 2010, earthquakes which are over 5.8 magnitudes happened 14 times and led to the fatalities achieving to around 0.1 million [33]. The Irpinia earthquake which took place on 23rd November 1980 $(\mathrm{MS}=6.9)$ caused about 3 thousand people dead, the destruction of 15 towns and severe damage within a radius near $50 \mathrm{~km} \mathrm{[34].} \mathrm{The} \mathrm{flood,} \mathrm{which} \mathrm{happened} \mathrm{in} \mathrm{the} \mathrm{Valle}$ d'Aosta, Piedmont and Liguria Regions (north-western Italy) during 13-16 October 2000, led to 35 deaths, 25 missing people and 5 thousands million Euros economic loss [35]. With regard to the catastrophic landslide within Italy, it occurred on the southern slope of the Vajont dam reservoir on 9th October 1963. Almost 1.9 thousand people lost their lives during this event [36].

Italy's total installed generation capacity was $124,750 \mathrm{MW}$ in 2013 [37]. Conventional thermal plants produced 80\%, hydroelectric $17 \%$, and other sources (non-nuclear) about $3 \%$ of the demand [38]. The consumption of electricity in 2013 was 297.3 TWh while net national production was 278.8 TWh [37], the rest was depended on the import.

In order to study the impact of natural threats on Italian power systems, especially the northwest part of Italy, we developed fully georeferenced models of the Italian transmission system with four typical power/demand snapshots (winter peak, winter off-peak, summer peak, summer off-peak) in 2014, then the worst case (in terms of post-contingency severity) "winter peak" was chosen. The georeferenced model of "winter peak" snapshot is shown in Figure 4. This snapshot contains a complete set of buses and branches (lines, transformers) of the 220-380 kV Italian transmission network.] Besides, network structures of important neighboring countries are simplified (The total numbers of buses, generators, lines, and transformers are around 1.2, 0.24, 1.4, and 0.2 thousand respectively). The maximum error of the power flow results, compared with the real network situation, is less than $2 \%$. In order to combine the power system with the geographic information [39], the longitude and latitude of each bus, generator, and transmission tower were found from Google maps and mapped into the Italian power transmission network. Therefore, this model gives the precise location of each element in the system. Overall, the georeferenced model is highly similar to the network that is being used by the Italian transmission system operator (Terna S.p.A) for operation from the perspective of the static power flow.

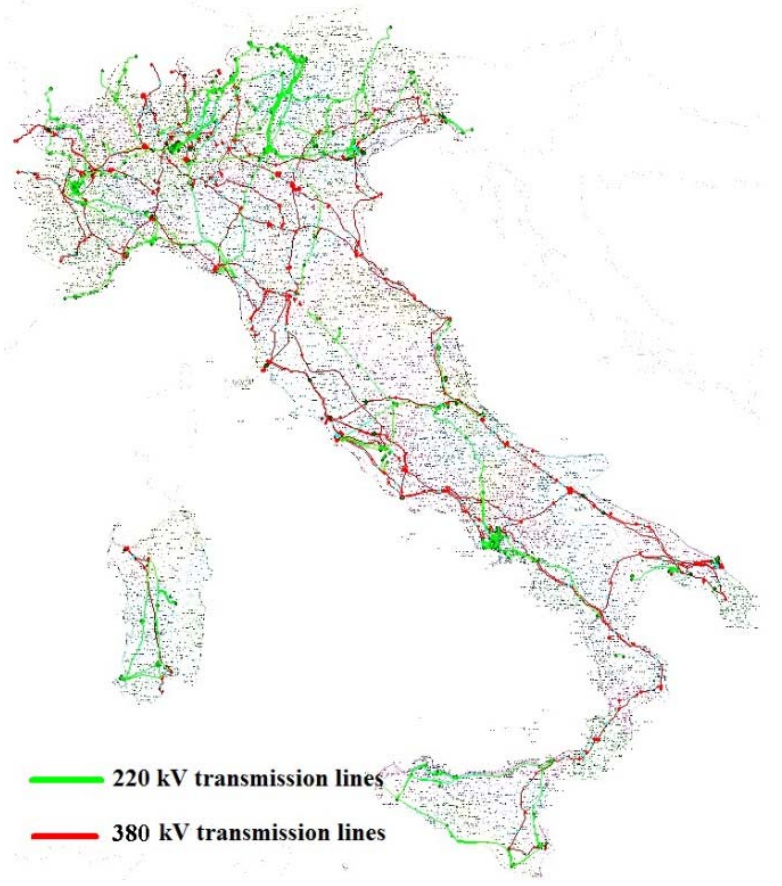

Figure 4. The georeferenced model of Italian power grid with administrative map

\subsection{Winter storm in the Alps}

The first case represents an extreme weather situation when the temperature in the Alps reaches $-45^{\circ} \mathrm{C}$ and the snowfall achieves to $11.5 \mathrm{~m}$ (according to the most extreme record in the Alps). The transmission corridor links up Switzerland with Italy by two lines (one from SRIDDE21 to IVALTA21 and the other one from SRIDDE21 to IAVITA21) passing through the Alps with the average altitude around 3.5 thousand meters (Figure 5). The towers for these two lines are hypothesized to be overwhelmed by the accumulated snow under this weather condition, so the two connections along this corridor with Switzerland are interrupted.

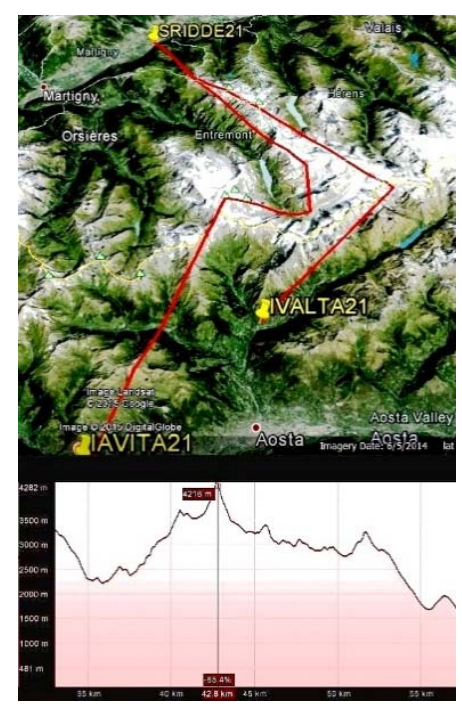

Figure 5. Italy-Switzerland electricity corridor (SRIDDE21-IVALTA21-IAVITA21 
The contingency analysis shows that an additional loss of lines can trigger system violations with high potentials to develop a blackout (Table 5). As an example, we report the overloads in Table 6 after tripping line ISGSR111ITERR111. The highest line flow can reach $210.9 \%$ of the rated MVA while no voltage violation is observed.

Table 5. Impact of top 5 contingencies in terms of branch overload

\begin{tabular}{|c|l|c|c|c|c|c|}
\hline No & \multicolumn{1}{|c|}{ Contingency Records } & $\begin{array}{c}\text { Isolated } \\
\text { Bus }\end{array}$ & $\begin{array}{c}\text { Disconnected } \\
\text { Load (MW) }\end{array}$ & $\begin{array}{c}\text { Disconnected } \\
\text { Generation } \\
\text { (MW) }\end{array}$ & $\begin{array}{c}\text { Voltage } \\
\text { \&line flow } \\
\text { violations }\end{array}$ & $\begin{array}{c}\text { Branch } \\
\text { overload } \\
\text { (\%) }\end{array}$ \\
\hline 1 & ISGSR111-ITERR111 & 0 & 0 & 0 & 4 & 210.9 \\
\hline 2 & IRMNR111-ISLUR111 & 0 & 0 & 0 & 10 & 207.3 \\
\hline 3 & $\begin{array}{l}\text { XRE_DI11- } \\
\text { IRDPVA11C1 }\end{array}$ & 0 & 0 & 0 & 6 & 184.4 \\
\hline 4 & IMCON111-ISSONA11 & 0 & 0 & 0 & 10 & 153.5 \\
\hline 5 & IRSRRA11-ITERR111 & 0 & 0 & 0 & 4 & 153.4 \\
\hline
\end{tabular}

Table 6. Branch overload after tripping line ISGSR111-ITERR111

\begin{tabular}{|c|l|c|c|c|}
\hline No. & Branch & $\begin{array}{c}\text { Value } \\
\text { (MVA) }\end{array}$ & $\begin{array}{c}\text { Limit } \\
\text { (MVA) }\end{array}$ & $\begin{array}{c}\text { Percent } \\
(\%)\end{array}$ \\
\hline 1 & ISGSR121 -IPR2R121 & 393.7 & 186.7 & 210.87 \\
\hline 2 & IPR2R121 -IVLVR121 & 464.86 & 304.8 & 152.51 \\
\hline 3 & IVLVR121 - IVLVR111 & 440.95 & 379.8 & 116.1 \\
\hline
\end{tabular}

Figure 6 shows, as an example, the visual comparison of the power flow before and after the contingencies. Manifestly, the contingency impacts the central part more severe than the rest of the country.

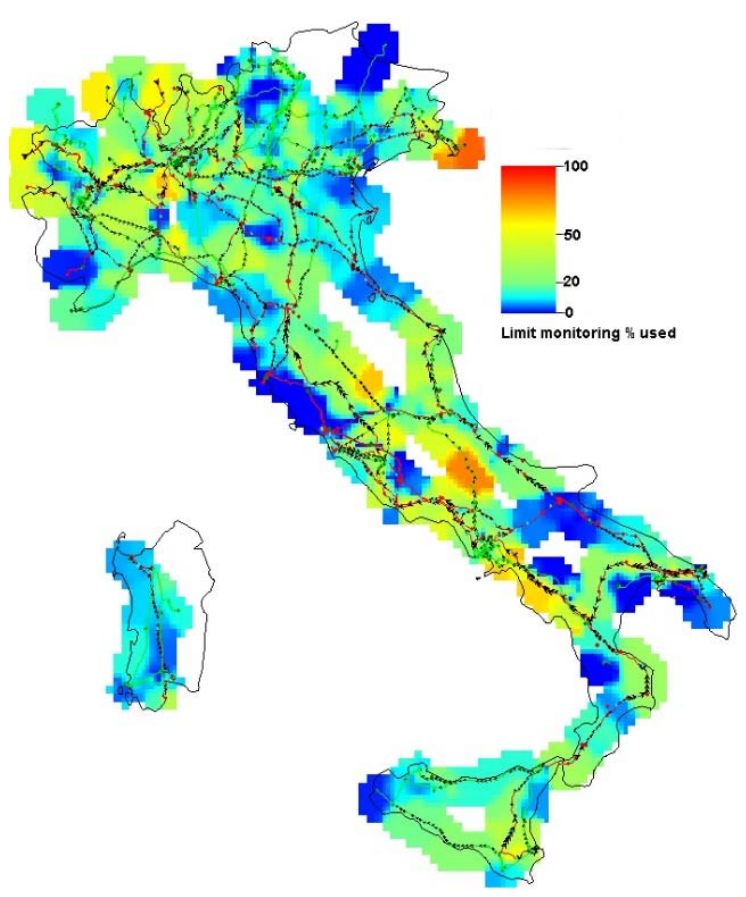

Figure 6. Comparison of power flow distribution for tripping line ISGSR111 - ITERR111

(a) Power flow distribution in normal state

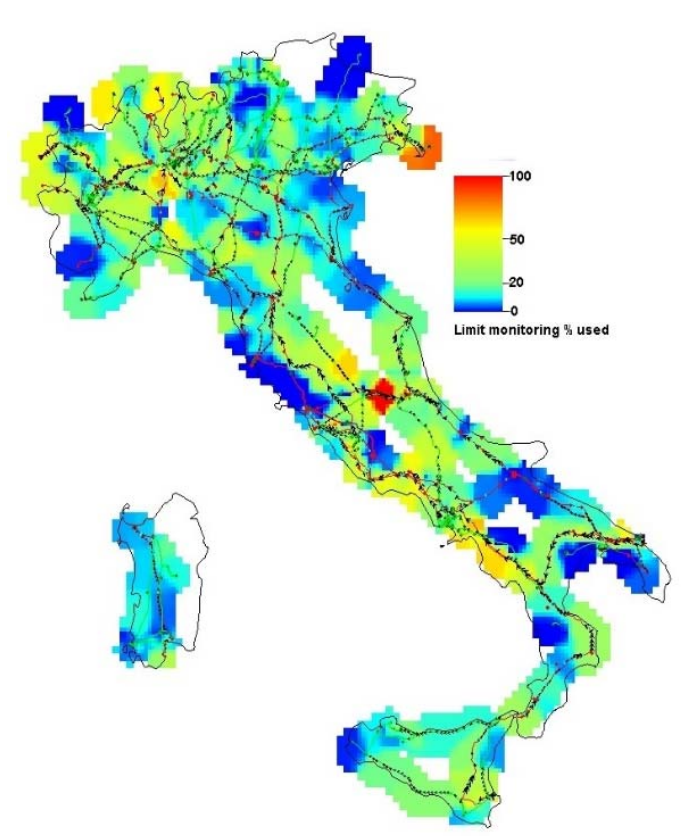

Figure 6. Comparison of power flow distribution for tripping line ISGSR111 - ITERR111

(b) Power flow distribution after tripping line ISGSR111 ITERR111

Besides the above reported severe contingencies which can directly cause serious violations, there are also potential risks to cause the collapse of transmission towers in the same area under the same weather situation. After the disconnection of the two considered tie-lines, power flows over the lines in the same area would decrease. This further leads to hinder melting the ice over the transmission lines. Then the accumulated ice would collapse the towers. To show the consequence, we present the result of the power flow on line IAVITA21 IVLNT121 as displayed in Table 7. It presents situations before and after the disconnection of the tie-lines, and the result is that corresponding power flow is decreased.

Table 7. Power flow on line IAVITA21 -IVLNT121 before and after opening the tie-lines

\begin{tabular}{|c|c|c|c|c|c|c|}
\hline & \multicolumn{2}{|c|}{ Before disconnecting } & \multicolumn{2}{c|}{ After disconnecting } & \multicolumn{2}{c|}{ Decrease } \\
\hline Line & $\begin{array}{c}\text { Line flow } \\
\text { (MVA) }\end{array}$ & $\begin{array}{c}\text { Used } \\
\text { percentage } \\
(\%)\end{array}$ & $\begin{array}{c}\text { Line flow } \\
\text { (MVA) }\end{array}$ & $\begin{array}{c}\text { Used } \\
\text { percentage } \\
(\%)\end{array}$ & $\begin{array}{c}\text { Line flow } \\
\text { (MVA) }\end{array}$ & $\begin{array}{c}\text { Used } \\
\text { percentage } \\
(\%)\end{array}$ \\
\hline $\begin{array}{l}\text { IAVITA21 - } \\
\text { IVLNT121 }\end{array}$ & 44.14 & 7.24 & 26.10 & 4.28 & 18.04 & 2.96 \\
\hline
\end{tabular}

\subsection{Dam collapse in France}

In the second case we consider a flood caused by the collapse of the dam of the hydroelectric reservoir of Lac $\mathrm{Du}$ Mont Cenis (the total storable volume amounts to about 320 million cubic meters, and the highest position is above sea level 2000 meters), which would involve densely populated urban areas such as cities of Turin, Vercelli, Alessandria, etc. Figure 7 presents the possible areas affected by the flood with the blue surface. 


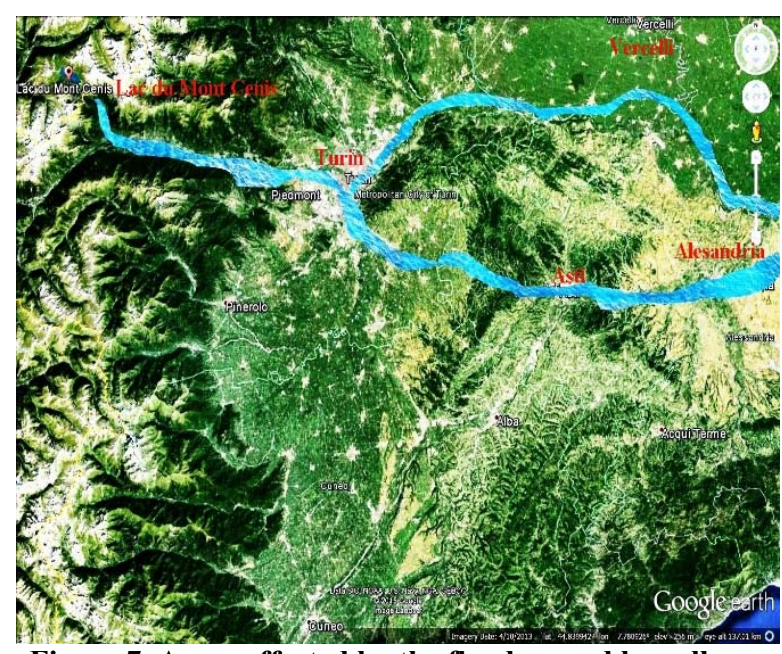

Figure 7. Areas affected by the flood caused by collapse of the Lac Du Mont Cenis dam

We preliminarily selected 25 important substations in the affected areas for the contingency set (ICHIT, IVNST, ICSNT, IPIOTA, IGRUTA, IMATT, IMAAT, IMOCT, IPELT, IPIATA, IPLTT, ISANT, ISTUT, ITCAT, ITCRT, ITOCT, ITONT, ITOWT, ITOST, ITRNT, ISLVT, IGERT, IFMIT, and IBALT). Table 8 reports a set of representative contingencies. The system will suffer from just one line flow violation when disconnecting substation ITONT alone, and the violation achieves $124 \%$. The isolation of all 25 substations disconnects the highest load $(1.13 \mathrm{GW})$, generation $(1.69 \mathrm{GW})$ and the largest set of isolating buses (38 buses). While disconnecting the substations individually, the largest disconnected load reaches $207 \mathrm{MW}$ but with the lowest amount of isolated bus ( 2 isolated buses) when isolating the substation ISTUT, and the largest disconnected generation arrives at $740 \mathrm{MW}$ when isolating the substation ITRNT.

Table 8. Power flow on line IAVITA21-IVLNT121 before and after opening the tie-lines

\begin{tabular}{|c|l|c|c|c|c|c|}
\hline No. & $\begin{array}{l}\text { Contingency } \\
\text { Records }\end{array}$ & Isolated Bus & $\begin{array}{l}\text { Disconnected } \\
\text { Load (MW) }\end{array}$ & $\begin{array}{l}\text { Disconnected } \\
\text { Generation (MW) }\end{array}$ & $\begin{array}{l}\text { Voltage } \\
\text { \&line flow } \\
\text { violations }\end{array}$ & $\begin{array}{c}\text { Branch } \\
\text { overload (\%) }\end{array}$ \\
\hline $\mathbf{1}$ & $\begin{array}{l}\text { ALL } \\
\text { Substations }\end{array}$ & $\mathbf{3 8}$ & 1130 & 1690 & 0 & 0 \\
\hline $\mathbf{2}$ & ISTUT & $\mathbf{2}$ & 207 & 0 & 0 & 0 \\
\hline $\mathbf{3}$ & ITRNT & $\mathbf{4}$ & 77 & 740 & 0 & 0 \\
\hline $\mathbf{4}$ & IMOAT & $\mathbf{3}$ & 68 & $\mathbf{5 8 7}$ & $\mathbf{0}$ & $\mathbf{0}$ \\
\hline $\mathbf{5}$ & ITONT & $\mathbf{5}$ & $\mathbf{3}$ & $\mathbf{3 1 4}$ & 1 & 124 \\
\hline
\end{tabular}

Figure 8 shows the negative consequence caused the flood. In Figure 8, the change of system voltage around affected areas can be observed, and it also implies the geographic coverage of the blackout with the administrative information. It is manifest that cities of Turin and Alessandria would be affected more heavily than other regions.

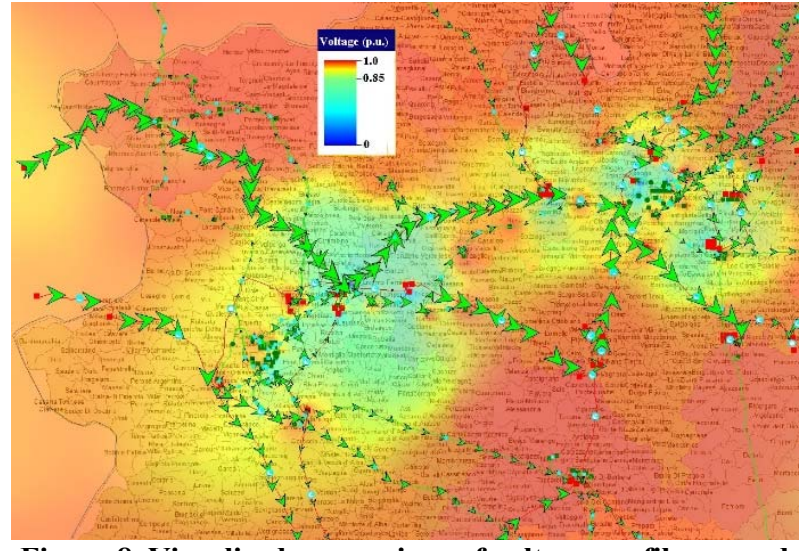

Figure 8. Visualized comparison of voltage profile around the affected area

(a) Voltage visualization around affected area before the event

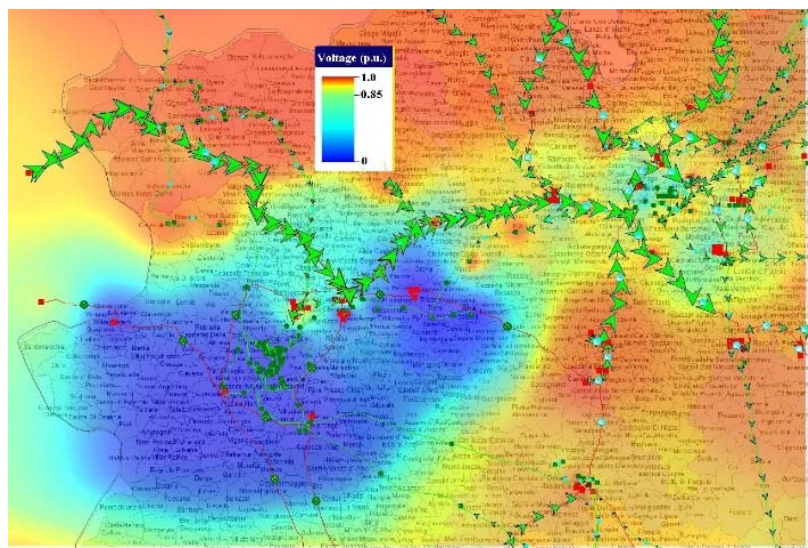

Figure 8. Visualized comparison of voltage profile around the affected area

(b) Voltage visualization around affected area after the event

\section{CONCLUSION}

Although no single failure will have a significant effect on the electricity system considering most utilities maintain sufficient generation and transmission reserves to withstand such failures, if a diversity of events (both natural and manmade) brings on several damages, substations, the transmission system and even loads would suffer from a great loss. Adverse natural events, as the unneglectable risk for power systems, happen rarely but their occurrences will lead to enormous losses for the society.

The large geographical exposure of power systems in the natural environment indicates the vulnerability of power grids when facing destructive adverse natural events. They do not only directly damage power facilities, but may also lead to blackouts through cascading failures. This would further result in huge economic loss and a large number of casualties. The gradually increasing population and electricity demand have a tendency to ascend losses for each country around the world. Therefore, it is necessary to have appropriate approaches and models to work on the influences of natural disasters 
on the power system. A possible way to achieve this is to put power systems data and geographical information together to establish the georeferenced model. The benefit is to allow us to plan, design, reinforce and manage power systems in a holistic way.

\section{REFERENCES}

[1] Z. L. R.R. Negenborn, H. Hellendoorn, Intelligent Infrastructures: Springer, 2010.

[2] D. S. James F. Petersen, Robert E. Gabler, Physical geography. Belmont, CA: Brooks/Cole, Cengage Learning 2012.

[3] N. C. D. C. National Oceanic and Atmospheric Administration, "Hurricane Katrina," 2005.

[4] E. Krausmann, A. M. Cruz, and B. Affeltranger, "The impact of the 12 May 2008 Wenchuan earthquake on industrial facilities," Journal of Loss Prevention in the Process Industries, vol. 23, pp. 242-248, 2010.

[5] W. Fang, "The impacts and corresponding measures of " 5.12 " Wenchuan earthquake on the power system of Sichuan province," Sichuan Water Power, vol. 28 , p. 6, 2009.

[6] T. A. o. N. California. Transmission Q\&A. Available:

http://www.tanc.us/transmission_qanda.html

[7] H. Rudnick, "Natural disasters, their impact on electricity supply," IEEE Power and Energy Magazine, 2011.

[8] B. Oral and F. Dönmez, "The Impacts of Natural Disasters on Power Systems: Anatomy of the Marmara Earthquake Blackout " Acta Polytechnica Hungarica, vol. 7, 2010.

[9] H. Hou, Yin, X., Chen, Q., You, D. and Tong, G., "Analysis and introspection of 2008 winter storm in China," Automatic of Electric Power System, vol. $32,2008$.

[10] J. Tiefenbacher, Approaches to Managing Disaster Assessing Hazards, Emergencies and Disaster Impacts. Rijeka, Croatia: InTech, 2012.

[11] T. a. T. Kanakubo, S, "Natural hazard mapping," GeoJournal, vol. 4, 1980.

[12] Ready.gov. (2013, 25 June). Natural Disasters Available: http://www.ready.gov/natural-disasters

[13] J. Kappenman, Geomagnetic Storms and Their Impacts on the U.S. Power Grid California Metatech Corporation 2010.

[14] Ready.gov. (2013). Natural Disasters Available: http://www.ready.gov/natural-disasters.

[15] Nhc.noaa.gov, "Tropical Cyclone Climatology," 2014.

[16] E. Bompard, T. Huang, Y. Wu, and M. Cremenescu, "Classification and trend analysis of threats origins to the security of power system," Electrical Power \& Energy Sytems, 2013.

[17] Emdat.be. (2013). EM-DAT Disaster Trends. Available:

http://www.emdat.be/disaster_trends/index.html
[18] Emdat.be. (2009). Maps - Disaster Types Available: http://www.emdat.be/maps-disaster-types

[19] N. L. Chiu, Hurricane Iwa, Hawaii, November 23, 1982. Washington, D.C.: National Academy Press, 1983.

[20] National Oceanic and Atmospheric Administration: National Weather Service, "Hurricane Iniki September 6 - 13,1992," 1992.

[21] M. Abley and J. Robinson, The ice storm. Toronto: M\&S, 1998.

[22] RMS, "The 1998 ice storm: 10-year retrospective," RMS2008.

[23] J. Cosgrave, "Tsunami Evaluation Coalition: Initial Findings," ALANP2006.

[24] L. S. Cluff, "Effects of the 2004 Sumatra-Andaman Earthquake and Indian Ocean Tsunami in Aceh Province " Engineering for the Threat of Natural Disasters, vol. 37, 2007.

[25] M. Hamada and T. Koike, Critical urban infrastructure handbook. Florida, U.S.: CRC Press, 2014.

[26] I. Forecasting, "Tohoku Earthquake \& Tsunami Event Recap Report. Impact Forecasting," Aon Benfield2011.

[27] World Meteorological Organization, The global climate 2001-2010, a decade of climate extremes summary report. Geneva: WMO, 2013.

[28] A. De Bono, Giuliani, G., Kluser, S. and Peduzzi, P, "Impacts of summer 2003 heat wave in Europe," UNEP2004.

[29] Energex.com.au. (2013). Energex power restoration fast facts at 1pm, Tuesday, 29 January - Queensland Energy - Energex. Available:

https://www.energex.com.au/media-centre/mediareleases/releases/2013/energex-power-restorationfast-facts-@-1pm,-tuesday,-29-january

[30] T. Overbye, "Visualization of power system data. System Sciences, 2000," Proceedings of the 33rd Annual Hawaii International Conference on, 2000.

[31] A. a. M. A.-R. M. AL - Sakkaf, B. (2011). Applications of GIS in Electrical Power System.

[32] Understandingitaly.com. Volcanoes in Italy Available:

http://www.understandingitaly.com/profilecontent/volcanoes.html

[33] Earthquake.usgs.gov. (2015). Historic World Earthquakes. Available:

http://earthquake.usgs.gov/earthquakes/world/histor ical_country.php\#italy

[34] F. Gizzi, Potenza, M. and Zotta, C, "23 November 1980 Irpinia-Basilicata earthquake (Southern Italy): towards a full knowledge of the seismic effects," Bulletin of Earthquake Engineering, vol. 10, pp. 1109-1131, 2012.

[35] F. C. Fausto Guzzetti, Oliviero Lolli, Stefania Pagliacci, Claudio Sebastiani, Gabriele Tonelli "Information System on Historical Landslides and Floods in Italy," presented at the Urban Hazards Forum, New York, 2002. 
[36] S. Bosa and M. Petti, "A Numerical Model of the Wave that Overtopped the Vajont Dam in 1963," Water Resources Management, vol. 27, pp. 17631779, 2012.

[37] Terna s.p.a, "Statistical Data on Electricity in Italy 2013," Terna2014.

[38] L. Salvaderi, "Electric sector restructuring in Italy," IEEE Power Engineering Review, vol. 20, pp. 12$16,2000$.

[39] Terna s.p.a. (2013, 25 Jun.). Dati Statistici: Rete elettrica. Available:

http://www.terna.it/LinkClick.aspx?fileticket=zrY9 HJFeFng\%3d\&tabid=418\&mid=2501 